\title{
Long non-coding RNA BCAR4 promotes liver cancer progression by regulating proliferation, migration and invasion
}

\author{
AIYAO WANG ${ }^{1}$, JUN MENG $^{1}, \mathrm{HUI} \mathrm{LIU}^{1}, \mathrm{CHEN} \mathrm{LI}^{2}$ and ZHIYONG ZHOU ${ }^{3}$ \\ Departments of ${ }^{1}$ Gastroenterology, ${ }^{2}$ Orthopedics and ${ }^{3}$ Oncology, Jiangxi Provincial People's \\ Hospital Affiliated to Nanchang University, Nanchang, Jiangxi 330006, P.R. China
}

Received February 3, 2019; Accepted September 6, 2019

DOI: $10.3892 / \mathrm{ol} .2020 .11826$

\begin{abstract}
Liver cancer (LC) is one of the primary contributors of cancer-associated death worldwide. Long non-coding RNAs (lncRNAs) have been shown to participate in almost every aspect of cell biology and serve fundamental roles in carcinogenesis and cancer progression, including in LC. However, the clinical significance and functional role of the lncRNA breast cancer anti-estrogen resistance 4 (BCAR4) in LC have not yet been identified. The present study measured the expression levels of BCAR4 in LC cells and tissues, and discovered that BCAR4 was upregulated in LC tissues compared with adjacent normal tissues. Furthermore, high BCAR4 expression was associated with the presence of multiple tumors and advanced Tumor-Node-Metastasis stages (III/IV). Survival analysis found that high BCAR4 expression indicated poor overall survival (OS) and progression-free survival (PFS). By analyzing the risk factors of poor OS and PFS using univariate analysis and multivariate analysis, high BCAR4 expression was revealed to be an independent risk factor of poor prognosis. In addition, the role of BCAR4 was further investigated in vitro, which revealed overexpression of BCAR4 to markedly promote the proliferation, migration and invasion of LC cells. Conversely, the loss of BCAR4 expression repressed the proliferation, migration and invasion of LC cells. In conclusion, BCAR4 is overexpressed in LC and is associated with LC progression. Therefore, BCAR4 may be used as a potential prognostic marker in LC.
\end{abstract}

\section{Introduction}

Liver cancer (LC), the third leading cause of cancer-associated mortality and the sixth most common cancer worldwide in 2016, represents a global health problem (1). The majority of

Correspondence to: Professor Zhiyong Zhou, Department of Oncology, Jiangxi Provincial People's Hospital Affiliated to Nanchang University, 92 Aiguo Road, Nanchang, Jiangxi 330006, P.R. China

E-mail: zhiyongzhoujxhos@aliyun.com

Key words: BCAR4, hepatocellular cancer, prognosis patients with LC are diagnosed at advanced stages due to the insidious developmental process (2). Curative therapies such as resection or transplantation are not suitable for patients with advanced stage LC, and advanced LCs are resistant to the majority of standard chemotherapeutic regimens (3). Therefore, the overall survival (OS) of patients with LC is dismal, with a five-year survival rate of $<15 \%$ in USA (3-5). Therefore, current research efforts are directed towards the discovery of biomarkers for early diagnosis, recognition of molecular subclasses of LC, correlation of molecular signatures with radiological/histological features, characterization of new therapeutic targets and personalization of therapies based on an individual's tumor biology (6). Further investigations into the mechanisms of carcinogenesis and development of LC are essential to achieve these goals.

In the past few decades, intensive investigations have focused on the role of protein-coding genes in the pathogenesis of LC (7-10). However, only $2 \%$ of the human genome is transcribed into protein-coding mRNAs, whereas $70-80 \%$ of the genome is actively transcribed into non-coding RNAs $(11,12)$. Long non-coding RNAs (lncRNAs) are the non-coding RNAs, $>200$ nucleotides in length, without protein-coding ability (13). Accumulating evidence has suggested that lncRNAs affect all essential processes in living cells, including chromatin condensation, replication, transcription, splicing, and translational and post-translational modification of proteins and constituting the most abundant part of the transcribed genome (14). In addition, a number of IncRNAs have been discovered since the discovery and characterization of the first lncRNA H19, in 1991 (15). In addition, current evidence has identified lncRNAs as key regulators of cancer signaling networks and characteristic cancer behaviors (16). Some lncRNAs, such as H19, HOX transcript antisense intergenic RNA, metastasis associated lung adenocarcinoma transcript 1 and lncRNA associated with microvascular invasion in HCC, were suggested to be dysregulated in LC and may serve as prognostic markers and therapeutic targets in patients with LC $(6,15,17-21)$. However, the clinical significance and functional role of breast cancer anti-estrogen resistance 4 (BCAR4) in LC have not yet been reported.

The present study aimed to investigate the expression levels of BCAR4 in LC cells and tissues. Furthermore, the clinical significance of BCAR4 in LC was explored, and its prognostic value was investigated, with the purpose of evaluating the functional role of BCAR4 in LC cells. 


\section{Materials and methods}

Collection of clinical specimens and follow-up. Tumor tissues and paired normal adjacent tissues were collected from 188 patients with LC (65 males and 35 females; median age, 62.3 years; range, 39-86 years), who underwent surgical resection between April 2011 and May 2014 at The Jiangxi Provincial People's Hospital Affiliated with Nanchang University (Nanchang, China). Adjacent tissues were obtained $\geq 2 \mathrm{~cm}$ away from the border of tumor tissues. The final diagnosis of patients was confirmed by pathology. None of the patients received preoperative chemotherapy, radiotherapy or other anticancer treatments. The specimens were collected immediately following surgical resection, and the collected tissues were frozen in liquid nitrogen and stored at $-80^{\circ} \mathrm{C}$ until further use. The clinicopathological characteristics of the patients analyzed in the present study included details of age, sex, serum $\alpha$-fetoprotein (AFP) level, alcoholism, hepatitis B virus (HBV) infection, liver cirrhosis, differentiation grade (American Joint Committee on Cancer) (22), tumor size, encapsulation, number of tumors, lymph-vascular space invasion (LVSI), and Tumor-Node-Metastasis (TNM) stage (American Joint Committee on Cancer) (22). Written informed consent was obtained from each patient and the present study was approved by The Ethnic Committee of Jiangxi Provincial People's Hospital Affiliated with Nanchang University.

Follow-up was performed by telephone interview and questionnaire every 3 months. The deadline of the follow-up was June 2017. OS was defined as the time interval between the date of diagnosis and the end of the follow-up, or the date at which the patient succumbed to the disease. Progression-free survival (PFS) was defined as the interval between the date of surgery and recurrence; if recurrence was not diagnosed, the patients were censored on the date of death or the last follow-up.

Cell culture and transfection. Liver cancer cell lines (HuH-6, Hep3B, HuH-7, HepG2, and HuH-1) were purchased from The Cell Bank of Type Culture Collection of the Chinese Academy of Sciences. HuH-6 and HuH-1 were cultured in RPMI-1640 medium (Invitrogen; Thermo Fisher Scientific, Inc.), whereas Hep3B, HuH-7 and HepG2 were cultured in DMEM (Invitrogen; Thermo Fisher Scientific, Inc.) supplemented with 10\% FBS (Thermo Fisher Scientific, Inc.), $100 \mathrm{U} / \mathrm{ml}$ penicillin and $100 \mathrm{mg} / \mathrm{ml}$ streptomycin (Thermo Fisher Scientific, Inc.) in a humidified atmosphere containing $5 \% \mathrm{CO}_{2}$ at $37^{\circ} \mathrm{C}$.

The BCAR4 expression vector (pcDNA3.1-BCAR4), a negative control vector (pcDNA3.1-Vector), specific small interfering RNAs (siRNAs) targeting BCAR4 (siBCAR4-1 and siBCAR4-2; cat. no. A01002) and a scrambled negative control (siNC; cat. no. A06001) were purchased from Shanghai GenePharma Co., Ltd,. The overexpression and silencing of BCAR4 were conducted using pcDNA3.1-BCAR4 (800 ng) and the siRNAs (siBCAR4-1 and siBCAR4-2; $50 \mathrm{nM}$ ), respectively. Transfection was performed using the Lipofectamine ${ }^{\circledR}$ 2000 reagent (Thermo Fisher Scientific Inc.) according to the manufacturer's instructions. Cells were subjected to subsequent experimentation $48 \mathrm{~h}$ following transfection.

Reverse transcription-quantitative PCR assay (RT-qPCR). Total RNA from the tissue samples and the transfected cells were extracted using the TRIzol reagent (Invitrogen; Thermo Fisher Scientific, Inc.) according to the manufacturer's protocol. The concentration and purity of RNA were determined by measuring its optical density (OD) using a NanoDrop 2000 spectrophotometer $(1.8<$ A260/280 $<2.0$; Thermo Fisher Scientific, Inc.). Total RNA (1 $\mu \mathrm{g})$ was reverse transcribed in a final volume of $20 \mu \mathrm{l}$, under standard conditions $\left(37^{\circ} \mathrm{C}\right.$ for $15 \mathrm{~min}$, then $85^{\circ} \mathrm{C}$ for $5 \mathrm{sec}$ ), using PrimeScript RT Reagent kit (Takara Biotechnology Co., Ltd.). qPCR was performed using an ABI PRISM 7000 Fluorescent Quantitative PCR system (Applied Biosystems; Thermo Fisher Scientific, Inc.) according to the manufacturer's protocols. Briefly, reactions were loaded onto a 96-well plate in triplicate and the thermocycling conditions used were: $95^{\circ} \mathrm{C}$ For $5 \mathrm{~min}$; followed by 40 cycles of denaturation at $95^{\circ} \mathrm{C}$ for $30 \mathrm{sec}, 1 \mathrm{~min}$ of annealing at $60^{\circ} \mathrm{C}$ and extension at $60^{\circ} \mathrm{C}$ for $1 \mathrm{~min}$. The average value of triplicate samples was used to calculate the relative expression of BCAR4 using the $2^{-\Delta \Delta \mathrm{Cq}}$ method (23). The experiments were repeated at least three times. The primer sequences were as follows: BCAR4 forward, 5'-TACAACCACTGCACTACCTG-3' and reverse, 5'-TGGAATGCTTGAAGGCTGCT-3'; and GAPDH, forward, 5'-CGCTCTCTGCTCCTCCTGTTC-3' and reverse, 5'-ATCCGTTGACTCCGACCTTCAC-3'. GAPDH was used as the internal control.

MTT and colony-formation assays. A Cell Proliferation Reagent kit I (MTT) (Roche Diagnostics) was used to assess cell proliferation. Transfected cells $\left(2 \times 10^{3}\right.$ per well) were plated in each well of a 96-well plate, dimethyl sulfoxide was used to dissolve the purple formazan, and the optical density was assessed at specific time points $(0,24,48,72$, and $96 \mathrm{~h})$ at a wavelength of $490 \mathrm{~nm}$, according to the manufacturer's protocol.

For the colony-formation assay, each well in a 6-well culture plate was seeded with $1 \times 10^{3}$ cells and cultured for 7 days in DMEM (Invitrogen; Thermo Fisher Scientific, Inc.) supplemented with $10 \%$ FBS, $100 \mathrm{U} / \mathrm{ml}$ penicillin and $100 \mathrm{mg} / \mathrm{ml}$ streptomycin (all Thermo Fisher Scientific, Inc.). Subsequently, the adherent cells were washed with PBS, fixed with $10 \%$ paraformaldehyde for $10 \mathrm{~min}$ at room temperature and stained with $1 \%$ crystal violet for $5 \mathrm{~min}$ at room temperature. Images of culture plates were captured using a light microscope (magnification, $\mathrm{x} 40$ ), and the number of colonies was counted. Triplicate wells were measured in each treatment group.

Transwell migration and invasion assays. After $48 \mathrm{~h}$ of transfection, cells $\left(1 \times 10^{5}\right)$ were resuspended in fresh medium (200 $\mu \mathrm{l})$ and added to the upper side of a Transwell chamber (8- $\mu \mathrm{m}$ pore size; BD Biosciences), uncoated (for the Transwell migration assay) or coated (for the Matrigel invasion assay) with $50 \mu \mathrm{l}$ Matrigel (BD Biosciences). Medium (700 $\mu \mathrm{l}$ ) containing $20 \%$ FBS was added to the lower chamber. After $24 \mathrm{~h}$ of incubation, the cells remaining on the upper membrane were removed using cotton wool. The migrated/invaded cells on the bottom side of the chamber were fixed with $4 \%$ paraformaldehyde for $30 \mathrm{~min}$ at room temperature and stained with Giemsa (Beijing Zhongsheng Ruitai Technology Co., Ltd.; 1:10 dilution) for $30 \mathrm{~min}$ at room temperature. Cell numbers were counted in 5 random fields of each chamber under the light microscope (magnification, $\mathrm{x} 40$ ). 
A

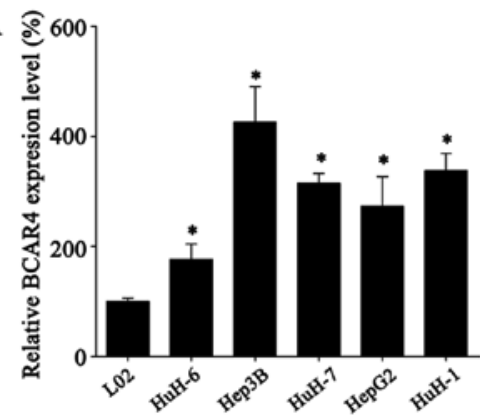

C

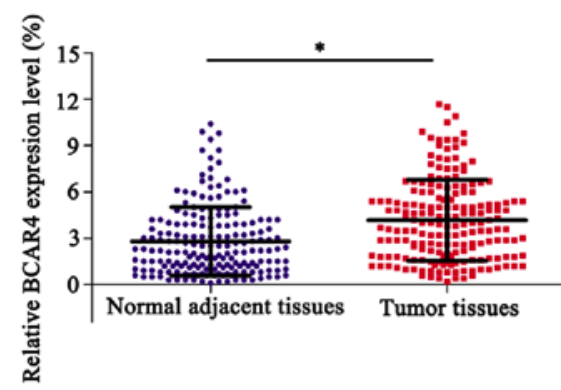

E

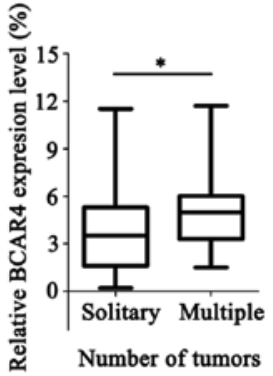

B

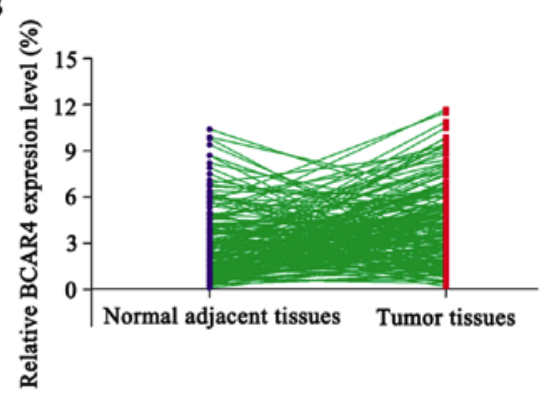

D ̊

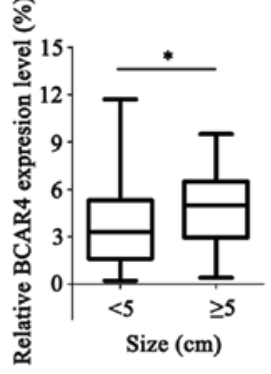

$\mathrm{F}$ ஓ

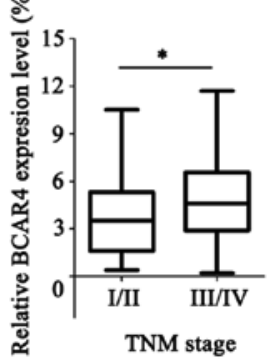

Figure 1. BCAR4 is overexpressed in LC and is associated with cancer progression. (A) Expression of BCAR4 was detected in five LC cell lines by RT-qPCR. (B) Expression of BCAR4 was measured in LC tissues and paired normal adjacent tissues $(\mathrm{n}=188)$ by RT- $\mathrm{qPCR}$. ${ }^{*} \mathrm{P}<0.05$. (C) The expression level of BCAR4 in LC tissues and paired normal adjacent tissues $(n=188)$ was statistically analyzed. The expression levels of BCAR4 in LC patients with (D) tumor size $\geq 5 \mathrm{~cm}$ and $<5 \mathrm{~cm}$, (E) solitary tumor and multiple tumors, and (F) less advanced TNM stages (I/II) and advanced TNM stages (III/IV) were detected and calculated by RT-qPCR. ${ }^{*} \mathrm{P}<0.05$. LC, liver cancer; BCAR4, breast cancer anti-estrogen resistance 4; RT-q, reverse transcription-quantitative; TNM, Tumor-Node-Metastasis.

Statistical analysis. All statistical analyses were performed using SPSS version 20.0 (IBM Corp.). The $\chi^{2}$ test and Student's $\mathrm{t}$-test were performed to examine the associations between BCAR4 expression level and clinical characteristics. Paired and unpaired Student's t-test were used to compare the difference between paired and independent samples, respectively. A one-way ANOVA with a post-hoc Dunnett's test was used to detect differences between multiple groups. The survival curves were plotted using the Kaplan-Meier method and a log-rank test was used to evaluate the differences between the survival curves. Hazard ratio (HR) and $95 \%$ confidence interval $(95 \% \mathrm{CI})$ values were calculated using a Cox proportional hazard regression model to evaluate the association between BCAR4 expression and OS/PFS. Variables with a value of $\mathrm{P}<0.05$ in univariate analysis were subjected to multivariate analysis on the basis of Cox regression analyses. $\mathrm{P}<0.05$ was considered to indicate a statistically significant difference.

\section{Results}

BCAR4 is overexpressed in LC and is associated with cancer progression. Determining the expression levels of
lncRNAs is a pivotal aspect in analyzing their potential role in cancer. In order to investigate the functional role of BCAR4 in LC, its expression levels in five LC cell lines (HuH-6, Hep3B, HuH-7, HepG2 and HuH-1) were measured by RT-qPCR. BCAR4 displayed varying expression levels in LC cells; Hep3B cells exhibited the highest expression level of the 4 LC cell lines, while HepG2 cells expressed the lowest levels, and the difference in expression between the aforementioned cell lines was significant (Fig. 1A). The expression of BCAR4 was detected in $188 \mathrm{LC}$ tissues and paired normal adjacent tissues (Fig. 1B). LC tissues exhibited significantly higher levels of BCAR4 expression compared with the paired normal adjacent tissues $(\mathrm{P}<0.05$; Fig. 1C). Additionally, patients with tumor sizes $\geq 5 \mathrm{~cm}$, multiple tumors and advanced TNM stages (III/IV) showed significantly higher expression levels of BCAR4 compared with those with tumor size $<5 \mathrm{~cm}(\mathrm{P}<0.05$; Fig. 1D), solitary tumors $(\mathrm{P}<0.05$; Fig. 1E) and less advanced TNM stages (I/II) $(\mathrm{P}<0.05$; Fig. $1 \mathrm{~F})$, respectively.

In order to determine the clinical significance of BCAR4 in LC, patients were divided into a low-BCAR4 expression group $(\mathrm{n}=100)$ and a high-BCAR4 expression group $(\mathrm{n}=88)$. 
Table I. Association between BCAR4 expression and clinicopathological characteristics of hepatocellular carcinoma.

\begin{tabular}{|c|c|c|c|}
\hline \multirow[b]{2}{*}{ Parameters } & \multicolumn{2}{|c|}{ No. of patients } & \multirow[b]{2}{*}{ P-value } \\
\hline & Low BCAR4 expression, $n=100$ & High BCAR4 expression, $\mathrm{n}=88$ & \\
\hline Age, years & & & 0.970 \\
\hline$<55$ & 52 & 46 & \\
\hline$\geq 55$ & 48 & 42 & \\
\hline Sex & & & 0.137 \\
\hline Male & 65 & 66 & \\
\hline Female & 35 & 22 & \\
\hline AFP, ng/ml & & & 0.862 \\
\hline$<20$ & 51 & 46 & \\
\hline$\geq 20$ & 49 & 42 & \\
\hline Alcoholism & & & 0.586 \\
\hline Negative & 46 & 37 & \\
\hline Positive & 54 & 51 & \\
\hline $\mathrm{HBV}$ & & & 0.974 \\
\hline Negative & 18 & 16 & \\
\hline Positive & 82 & 72 & \\
\hline Liver cirrhosis & & & 0.505 \\
\hline Present & 44 & 43 & \\
\hline Absent & 56 & 45 & \\
\hline Differentiation grade & & & 0.320 \\
\hline Well + moderate & 62 & 58 & \\
\hline Poor & 38 & 30 & \\
\hline Tumor size, $\mathrm{cm}$ & & & 0.089 \\
\hline$<5$ & 73 & 54 & \\
\hline$\geq 5$ & 27 & 34 & \\
\hline Encapsulation & & & 0.784 \\
\hline No & 48 & 44 & \\
\hline Complete & 52 & 44 & \\
\hline Number of tumors & & & 0.029 \\
\hline Solitary & 81 & 59 & \\
\hline Multiple & 19 & 29 & \\
\hline LVSI & & & 0.122 \\
\hline Present & 41 & 46 & \\
\hline Absent & 59 & 42 & \\
\hline TNM stage & & & 0.020 \\
\hline $\mathrm{I} / \mathrm{II}$ & 75 & 52 & \\
\hline III/IV & 25 & 36 & \\
\hline
\end{tabular}

AFP, $\alpha$-fetoprotein; BCAR4, breast cancer anti-estrogen resistance 4; HBV, hepatitis B virus; LVSI, Lymph-vascular space invasion; TNM, Tumor-Node-Metastasis.

The average BCAR4 expression level was used as the cut-off value. The association between BCAR4 expression levels and the clinicopathological characteristics of LC was statistically analyzed. Higher levels of BCAR4 expression were associated with the presence of multiple tumors and advanced TNM stages (III/IV) (Table I). Overall, high BCAR4 expression is associated with the clinical progression of LC.
High BCAR4 expression predicts poor prognosis in LC. A lack of prognostic markers with adequate efficiency and efficacy complicates individualized therapeutic regimens in clinical practice. The present study evaluated the prognostic value of high BCAR4 expression in LC. Patients with high BCAR4 expression exhibited poorer OS time $(\mathrm{P}<0.01$; Fig. $2 \mathrm{~A})$ and PFS time $(\mathrm{P}<0.01$; Fig. $2 \mathrm{~B})$ compared with patients with low BCAR4 expression. 
Table II. Univariate analysis of clinicopathological features, OS and PFS of hepatocellular carcinoma patients.

\begin{tabular}{|c|c|c|c|c|c|c|}
\hline \multirow[b]{2}{*}{ Parameters } & \multicolumn{3}{|c|}{ OS } & \multicolumn{3}{|c|}{ PFS } \\
\hline & HR & $95 \% \mathrm{CI}$ & P-value & HR & $95 \% \mathrm{CI}$ & P-value \\
\hline Age, years ( $\geq 55$ vs. $<55)$ & 1.373 & $0.950-1.984$ & 0.092 & 1.332 & $0.925-1.918$ & 0.124 \\
\hline Sex (male vs. female) & 1.011 & $0.679-1.505$ & 0.959 & 1.061 & $0.718-1.568$ & 0.767 \\
\hline AFP, ng/ml (<20 vs. $\geq 20)$ & 1.127 & $0.780-1.628$ & 0.523 & 1.148 & $0.798-1.652$ & 0.458 \\
\hline Alcoholism (negative vs. positive) & 1.179 & $0.813-1.710$ & 0.386 & 1.197 & $0.827-1.732$ & 0.341 \\
\hline HBV (negative vs. positive) & 1.045 & $0.639-1.711$ & 0.860 & 0.957 & $0.596-1.535$ & 0.855 \\
\hline Liver cirrhosis (present vs. absent) & 1.082 & $0.749-1.563$ & 0.674 & 1.074 & $0.746-1.547$ & 0.699 \\
\hline Differentiation grade (poor vs. well + moderate) & 0.865 & $0.58-1.271$ & 0.461 & 0.833 & $0.568-1.222$ & 0.350 \\
\hline Tumor size, cm ( $\geq 5$ vs. $<5)$ & 1.623 & $1.109-2.374$ & 0.013 & 1.587 & $1.087-2.316$ & 0.017 \\
\hline Encapsulation (no vs. complete) & 1.257 & $0.870-1.817$ & 0.224 & 1.287 & $0.893-1.855$ & 0.177 \\
\hline No. of tumors (multiple vs. solitary) & 1.986 & $1.333-2.957$ & 0.001 & 1.934 & $1.301-2.876$ & 0.001 \\
\hline LVSI (present vs. absent) & 2.036 & $1.401-2.959$ & $<0.001$ & 2.087 & $1.441-3.023$ & $<0.001$ \\
\hline TNM stage (III/IV vs. I/II) & 3.333 & $2.289-4.853$ & $<0.001$ & 3.165 & $2.181-4.593$ & $<0.001$ \\
\hline BCAR4 (high vs. low) & 1.157 & $1.076-1.244$ & $<0.001$ & 1.138 & $1.059-1.223$ & $<0.001$ \\
\hline
\end{tabular}

OS, overall survival; PFS, progression-free survival; HR, hazard ratio; CI, confidence interval; AFP, alpha-fetoprotein; HBV, hepatitis B virus; LVSI, Lymph-vascular space invasion; TNM, Tumor-Node-Metastasis; BCAR4, breast cancer anti-estrogen resistance 4.

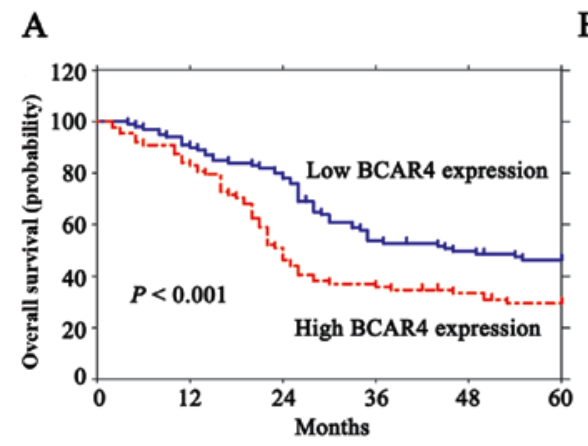

B
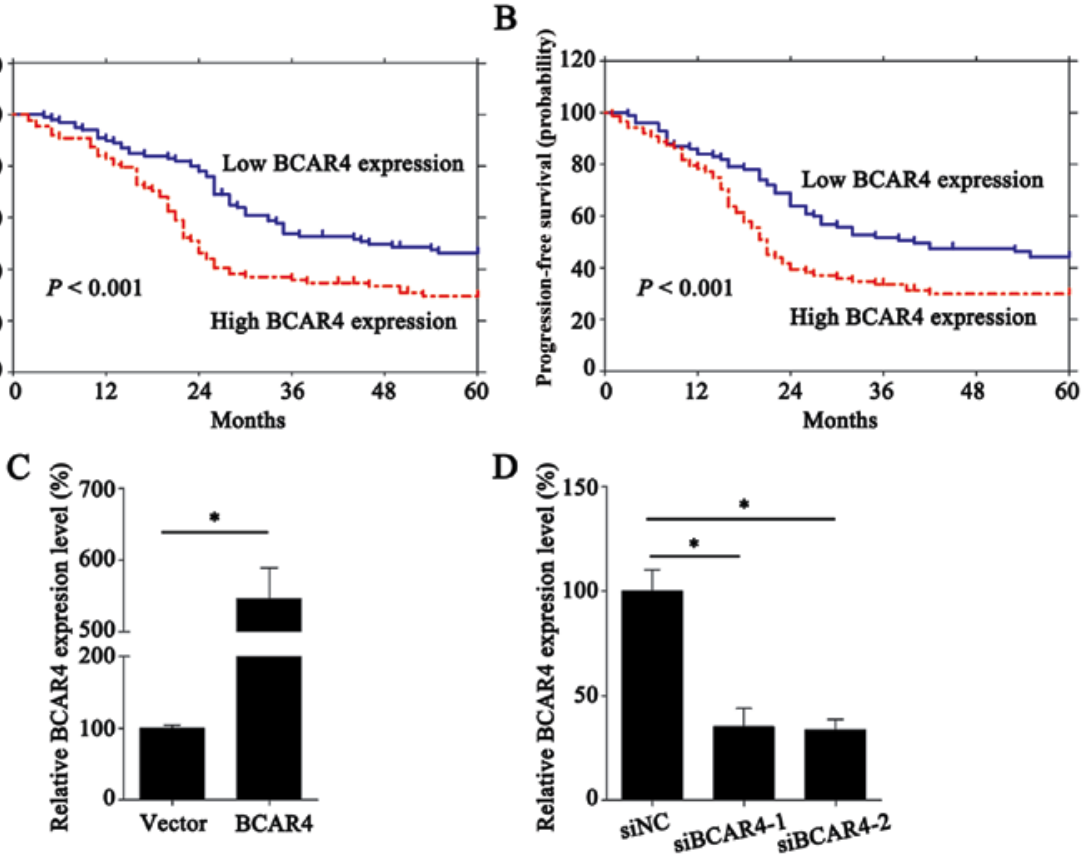

Figure 2. Overexpression of BCAR4 predicts poor prognosis in LC. (A) Overall survival and (B) progression-free survival of patients with LC in the low-BCAR4 expression group and the high-BCAR4 expression group are shown as Kaplan-Meier curves and compared using a log-rank test. (C) RT-qPCR was used to detect the expression of BCAR4 in HuH-6 cells overexpressing BCAR4 and (D) in Hep3B cells with BCAR4 knocked down. "P<0.05. LC, liver cancer; BCAR4, breast cancer anti-estrogen resistance 4; RT-q, reverse transcription-quantitative; si, small interfering RNA; NC, negative control.

Univariate analysis and multivariate analysis were performed to identify the risk factors of poor OS. Five parameters (tumor size $\geq 5 \mathrm{~cm}$, multiple tumors, presence of LVSI, TNM stages III/IV and high BCAR4 expression) were shown to be risk factors of poor OS and PFS in the univariate analysis (Table II). Further analysis of these factors using multivariate analysis found that the presence of LVSI ( $\mathrm{P}=0.001$; HR, 1.943; 95\% CI, 1.319-2.862), TNM stages III/IV ( $\mathrm{P}<0.001 ; \mathrm{HR}, 3.418$; 95\% CI, 2.156-5.420) and high BCAR4 expression ( $\mathrm{P}=0.002$; HR, 1.126; $95 \%$ CI, 1.046-1.212,) were independent risk factors of poor OS (Table III). In addition, the presence of LVSI $(\mathrm{P}<0.001$; HR, 2.009; 95\% CI, 1.372-2.941), TNM stage III/IV ( $\mathrm{P}<0.001$; HR, 3.253; 95\% CI, 2.061-5.137) and high BCAR4 expression $(\mathrm{P}=0.007$; HR, $1.105 ; 95 \% \mathrm{CI}, 1.027-1.189)$ were also demonstrated to be independent risk factors of poor PFS 
Table III. Multivariate analysis of clinicopathologic features and OS and PFS of patients with hepatocellular carcinoma.

\begin{tabular}{|c|c|c|c|c|c|c|}
\hline \multirow[b]{2}{*}{ Parameters } & \multicolumn{3}{|c|}{ OS } & \multicolumn{3}{|c|}{ PFS } \\
\hline & HR & $95 \% \mathrm{CI}$ & P-value & HR & $95 \% \mathrm{CI}$ & P-value \\
\hline Tumor size, $\mathrm{cm}(\geq 5$ vs. $<5)$ & 0.889 & $0.554-1.427$ & 0.626 & 0.889 & $0.556-1.421$ & 0.622 \\
\hline No. of tumors (multiple vs. solitary) & 0.836 & $0.491-1.423$ & 0.509 & 0.857 & $0.506-1.450$ & 0.564 \\
\hline LVSI (present vs. absent) & 1.943 & $1.319-2.862$ & 0.001 & 2.009 & $1.372-2.941$ & $<0.001$ \\
\hline TNM stage (III/IV vs. I/II) & 3.418 & $2.156-5.420$ & $<0.001$ & 3.253 & $2.061-5.137$ & $<0.001$ \\
\hline BCAR4 (high vs. low) & 1.126 & $1.046-1.212$ & 0.002 & 1.105 & $1.027-1.189$ & 0.007 \\
\hline
\end{tabular}

OS, overall survival; PFS, progression-free survival; HR, hazard ratio; CI, confidence interval; LVSI, Lymph-vascular space invasion; TNM, Tumor-Node-Metastasis; BCAR4, breast cancer anti-estrogen resistance 4.

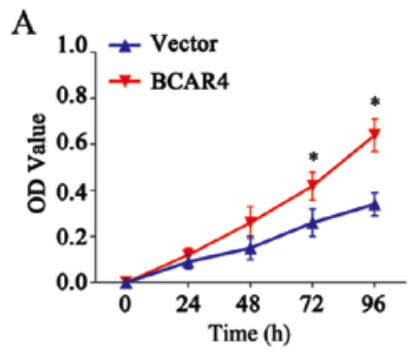

B
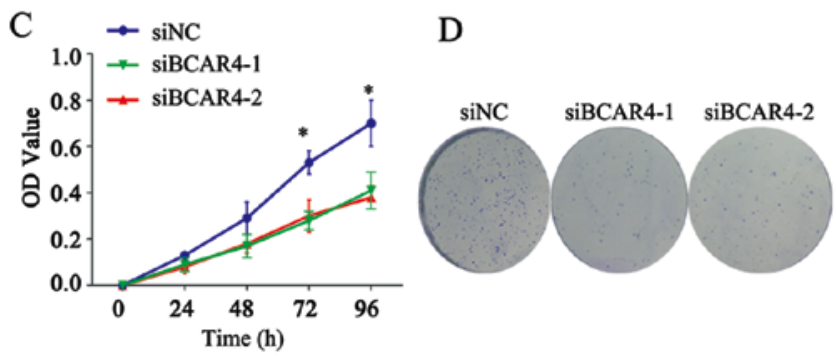
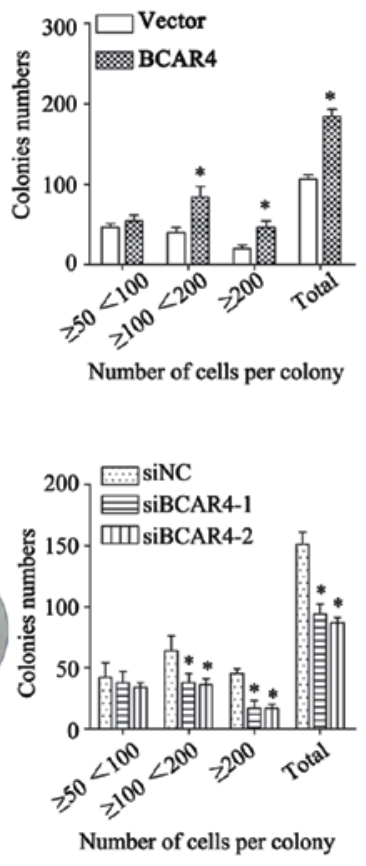

Figure 3. BCAR4 promotes proliferation of LC. (A) MTT and (B) colony-formation assays were conducted to evaluate the proliferation ability of HuH-6 cells overexpressing BCAR4. "P<0.05. (C) MTT and (D) colony-formation assays were performed to detect the proliferative ability of Hep3B cells with BCAR4 knocked down. "P<0.05. LC, liver cancer; BCAR4, breast cancer anti-estrogen resistance 4; si, small interfering RNA; NC, negative control; OD, optical density.

(Table III). Collectively, high BCAR4 expression predicts poor prognosis and serves as an independent risk factor of poor OS and PFS in LC.

$B C A R 4$ promotes proliferation, migration and invasion in $L C$. HuH-6 and Hep3B cells had the lowest and highest BCAR4 expression levels among the 5 LC cell lines used in this study, respectively (Fig. 1A). BCAR4 was ectopically overexpressed in HuH-6 cells (Fig. 2C) and silenced in Hep3B cells (Fig. 2D) for the functional assays. The proliferative abilities of LC cells with BCAR4 overexpression and knockdown were evaluated using MTT and colony-formation assays. Overexpression of BCAR4 resulted in increased OD values after 72 and $96 \mathrm{~h}$ $(\mathrm{P}<0.05$; Fig. $3 \mathrm{~A})$ and number of colonies $(\mathrm{P}<0.05$; Fig. $3 \mathrm{~B})$ in HuH-6 cells compared with the empty vector control; whereas BCAR4 knockdown significantly decreased the OD value
$(\mathrm{P}<0.05$; Fig. 3C) and the colony number ( $\mathrm{P}<0.05$; Fig. 3D) in Hep3B cells compared with siNC transfected cells. Moreover, overexpression of BCAR4 in HuH-6 cells significantly promoted migration $(\mathrm{P}<0.05$; Fig. $4 \mathrm{~A})$ and invasion $(\mathrm{P}<0.05$; Fig. 4B) compared with the empty vector control. Knockdown of BCAR4 in Hep3B cells resulted in reduced migration $(\mathrm{P}<0.05$; Fig. 4C) and invasion $(\mathrm{P}<0.05$; Fig. 4D) compared with cells transfected with siNC. Overall, these results suggest that BCAR4 promotes the proliferation, migration and invasion of LC cells.

\section{Discussion}

Several canonical signaling pathways have been indicated to mediate lncRNA-regulated behaviors in LC, such as Wnt signaling $(24,25)$ and STAT3 signaling (26-29). In addition, 
A

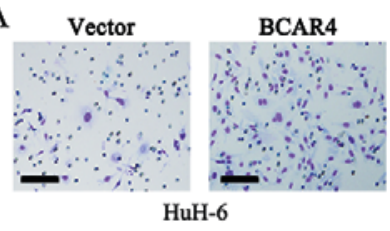

B Vector

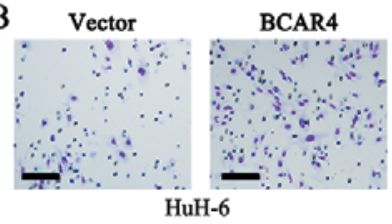

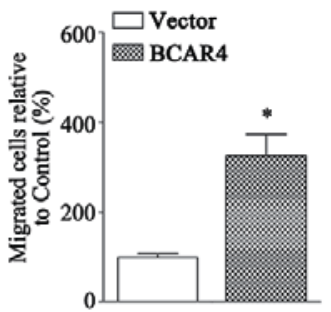
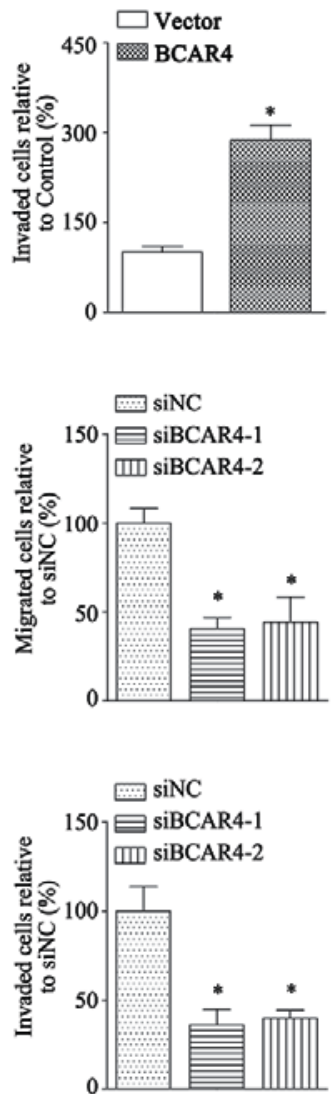

Figure 4. BCAR4 promotes migration and invasion in LC. (A) Migratory and (B) invasive abilities of HuH-6 cells overexpressing BCAR4 were measured using Transwell migration and Matrigel invasion assays. ${ }^{*} \mathrm{P}<0.05$. (C) Migration and (D) invasion of Hep3B cells with BCAR4 knocked down, were detected using Transwell migration and Matrigel invasion assays. Scale bars, $50 \mu \mathrm{m}$. ${ }^{*} \mathrm{P}<0.05$. LC, liver cancer; BCAR4, breast cancer anti-estrogen resistance 4 ; si, small interfering RNA; NC, negative control.

lncRNAs are involved in the determination and maintenance of hepatic cancer stem cell characteristics $(30,31)$ and the regulation of epithelial-to-mesenchymal transition (32-34). Furthermore, one study evaluated lncRNAs alone and in combination as candidate biomarkers for LC diagnosis, with reported sensitivities ranging from 91.4 to $92.7 \%$ and specificity ranging from 82.1 to $88.6 \%$ (18). 1ncRNAs have been considered as potential early diagnostic biomarkers in LC $(35,36)$. Additionally, some studies suggested that IncRNAs may be potential therapeutic targets in LC, owing to their tissue-specific expression patterns (19,37-39). Therefore, lncRNAs serve pivotal roles in LC biology and may shed new light on the early diagnosis and therapy for patients with LC.

In 2006, BCAR4 expression was first found to positively correlate with tamoxifen resistance, and ectopic expression of BCAR4 was shown to induce anti-estrogen resistance and anchorage-independent transformation of breast cancer (40); and this result was confirmed by additional studies (41-43). Further investigations performed by Godinho et al (44) found that BCAR4-positive breast tumors were driven by homologue 2/homologue 3 signaling. Therefore, BCAR4 was regarded as a suitable target for treating anti-estrogen-resistant breast cancer $(42,43)$. In addition, the oncogenic role of BCAR4 has been defined in osteosarcoma (45), colorectal cancer (46), non-small cell lung cancer (47), chondrosarcoma (48), gastric cancer (49) and glioma (50). Studies have revealed that BCAR4 promotes cancer progression through a number of mechanisms, such as increasing the metastatic behaviors of cells, proliferation, chemoresistance and epithelial-to-mesenchymal transition (45,47-50). Several signaling pathways, such as Wnt signaling and mTOR signaling, have been shown to mediate the functional role of BCAR4 in accelerating cancer progression $(48,51)$. The prognostic value of BCAR4 upregulation was reported in osteosarcoma, gastric cancer and colorectal cancer $(45,46,49)$. These findings lay a foundation for utilizing BCAR4 as a prognostic marker and therapeutic target in different types of cancer. However, the detailed mechanisms 
underlying the oncogenic functions of BCAR4 in LC are yet to be elucidated. Besides, the samples used in the present study were collected from a single medical center and the population size was limited; thus, more samples from multiple sources need to be analyzed to validate the present results.

The present study verified the upregulation of BCAR4 in LC, and its association with LC progression. Statistical analysis demonstrated that high BCAR4 expression indicated poor OS and PFS times. Furthermore, Cox regression analyses revealed high BCAR4 expression as an independent risk factor of poor OS and PFS. Furthermore, in vitro assays validated the effects of BCAR4 in promoting LC proliferation, migration and invasion. The present study indicates the potential of BCAR4 as a prognostic biomarker in LC.

\section{Acknowledgements}

Not applicable.

\section{Funding}

No funding was received.

\section{Availability of data and materials}

The datasets used and/or analyzed during the present study are available from the corresponding author on reasonable request.

\section{Authors' contributions}

$\mathrm{ZZ}$ and AW designed the study and revised the manuscript. JM, ZZ AW and HL performed the experiments. JM and HL drafted the manuscript. JM and CL performed statistical analysis of the data and conducted follow-up of the patients. All authors approved the final manuscript.

\section{Ethics approval and consent to participate}

Written informed consent was obtained from each patient and the present study was approved by The Ethnic Committee of Jiangxi Provincial People's Hospital Affiliated with Nanchang University.

\section{Patient consent for publication}

Not applicable.

\section{Competing interests}

The authors declare that they have no competing interests.

\section{References}

1. Siegel RL, Miller KD and Jemal A: Cancer statistics, 2016. CA Cancer J Clin 66: 7-30, 2016.

2. Ayoub WS, Steggerda J, Yang JD, Kuo A, Sundaram V and Lu SC: Current status of hepatocellular carcinoma detection: Screening strategies and novel biomarkers. Ther Adv Med Oncol 11: 1758835919869120, 2019.

3. Altekruse SF, McGlynn KA and Reichman ME: Hepatocellular carcinoma incidence, mortality, and survival trends in the United States from 1975 to 2005. J Clin Oncol 27: 1485-1491, 2009.
4. Alqahtani A, Khan Z, Alloghbi A, Said Ahmed TS, Ashraf M and Hammouda DM: Hepatocellular carcinoma: Molecular mechanisms and targeted therapies. Medicina (Kaunas) 55: E526, 2019.

5. Golabi P, Fazel S, Otgonsuren M, Sayiner M, Locklear CT and Younossi ZM: Mortality assessment of patients with hepatocellular carcinoma according to underlying disease and treatment modalities. Medicine (Baltimore) 96: e5904, 2017.

6. Dhanasekaran R, Venkatesh SK, Torbenson MS and Roberts LR: Clinical implications of basic research in hepatocellular carcinoma. J Hepatol 64: 736-745, 2016.

7. Cheng H, Sun G, Chen H, Li Y, Han Z, Li Y, Zhang P, Yang L and $\mathrm{Li} Y$ : Trends in the treatment of advanced hepatocellular carcinoma: Immune checkpoint blockade immunotherapy and related combination therapies. Am J Cancer Res 9: 1536-1545, 2019.

8. Kumari R, Sahu MK, Tripathy A, Uthansingh K and Behera M Hepatocellular carcinoma treatment: Hurdles, advances and prospects. Hepat Oncol 5: HEP08, 2018.

9. Neureiter D, Stintzing S, Kiesslich T and Ocker M: Hepatocellular carcinoma: Therapeutic advances in signaling, epigenetic and immune targets. World J Gastroenterol 25: 3136-3150, 2019.

10. Villanueva A: Hepatocellular carcinoma. N Engl J Med 380: 1450-1462, 2019.

11. Sana J, Faltejskova P, Svoboda M and Slaby O: Novel classes of non-coding RNAs and cancer. J Transl Med 10: 103, 2012.

12. ENCODE Project Consortium: An integrated encyclopedia of DNA elements in the human genome. Nature 489: 57-74, 2012.

13. Kopp F and Mendell JT: Functional classification and experimental dissection of long noncoding RNAs. Cell 172: 393-407, 2018.

14. Huang $B$ and Zhang R: Regulatory non-coding RNAs: Revolutionizing the RNA world. Mol Biol Rep 41: 3915-3923, 2014.

15. Smekalova EM, Kotelevtsev YV, Leboeuf D, Shcherbinina EY, Fefilova AS, Zatsepin TS and Koteliansky V: lncRNA in the liver: Prospects for fundamental research and therapy by RNA interference. Biochimie 131: 159-172, 2016.

16. Bartonicek N, Maag JL and Dinger ME: Long noncoding RNAs in cancer: Mechanisms of action and technological advancements. Mol Cancer 15: 43, 2016.

17. Niu ZS, Niu XJ and Wang WH: Long non-coding RNAs in hepatocellular carcinoma: Potential roles and clinical implications. World J Gastroenterol 23: 5860-5874, 2017.

18. Klingenberg M,Matsuda A,Diederichs S and Patel T: Non-coding RNA in hepatocellular carcinoma: Mechanisms, biomarkers and therapeutic targets. J Hepatol 67: 603-618, 2017.

19. Shibata C, Otsuka M, Kishikawa T, Ohno M, Yoshikawa T, Takata A and Koike K: Diagnostic and therapeutic application of noncoding RNAs for hepatocellular carcinoma. World J Hepatol 7: 1-6, 2015.

20. Sun J, Bie B, Zhang S, Yang J and Li Z: Long non-coding RNAs: Critical players in hepatocellular carcinoma. Int J Mol Sci 15: 20434-20448, 2014.

21. Shi L, Peng F, Tao Y, Fan X and Li N: Roles of long noncoding RNAs in hepatocellular carcinoma. Virus Res 223: 131-139, 2016.

22. Amin MB (ed): American Joint Committee on Cancer Staging Manual. 8th ed. Springer, New York, NY, 103-111, 2017.

23. Schmittgen TD and Livak KJ: Analyzing real-time PCR data by the comparative C(T) method. Nat Protoc 3: 1101-1108, 2008.

24. Yuan SX, Wang J, Yang F, Tao QF, Zhang J, Wang LL, Yang Y, Liu H, Wang ZG, Xu QG, et al: Long noncoding RNA DANCR increases stemness features of hepatocellular carcinoma by derepression of CTNNB1. Hepatology 63: 499-511, 2016.

25. Zhu P, Wang Y, Huang G, Ye B, Liu B, Wu J, Du Y, He L and Fan Z: lnc- $\beta$-Catm elicits EZH2-dependent $\beta$-catenin stabilization and sustains liver CSC self-renewal. Nat Struct Mol Biol 23: 631-639, 2016

26. Yuan JH, Yang F, Wang F, Ma JZ, Guo YJ, Tao QF, Liu F, Pan W, Wang TT, Zhou CC, et al: A long noncoding RNA activated by TGF- $\beta$ promotes the invasion-metastasis cascade in hepatocellular carcinoma. Cancer Cell 25: 666-681, 2014.

27. Zheng Q, Lin Z, Li X, Xin X, Wu M, An J, Gui X, Li T, Pu H, Li H and Lu D: Inflammatory cytokine IL6 cooperates with CUDR to aggravate hepatocyte-like stem cells malignant transformation through NF-kB signaling. Sci Rep 6: 36843, 2016.

28. Wang X, Sun W, Shen W, Xia M, Chen C, Xiang D, Ning B, Cui X, Li H, Li X, et al: Long non-coding RNA DILC regulates liver cancer stem cells via IL-6/STAT3 axis. J Hepatol 64: 1283-1294, 2016 
29. Lv L, Chen G, Zhou J, Li J and Gong J: WT1-AS promotes cell apoptosis in hepatocellular carcinoma through down-regulating of WT1. J Exp Clin Cancer Res 34: 119, 2015.

30. Wang F, Yuan JH, Wang SB, Yang F, Yuan SX, Ye C, Yang N, Zhou WP, Li WL, Li W and Sun SH: Oncofetal long noncoding RNA PVT1 promotes proliferation and stem cell-like property of hepatocellular carcinoma cells by stabilizing NOP2 Hepatology 60: 1278-1290, 2014.

31. Guo W, Liu S, Cheng Y, Lu L, Shi J, Xu G, Li N, Cheng K, Wu M, Cheng S and Liu S: ICAM-1-related noncoding RNA in cancer stem cells maintains ICAM-1 expression in hepatocellular carcinoma. Clin Cancer Res 22: 2041-2050, 2016.

32. Yang F, Huo XS, Yuan SX, Zhang L, Zhou WP, Wang F and Sun SH: Repression of the long noncoding RNA-LET by histone deacetylase 3 contributes to hypoxia-mediated metastasis. Mol Cell 49: 1083-1096, 2013.

33. Wang TH, Yu CC, Lin YS, Chen TC, Yeh CT, Liang KH, Shieh TM, Chen CY and Hsueh C: Long noncoding RNA CPS1-IT1 suppresses the metastasis of hepatocellular carcinoma by regulating HIF- $1 \alpha$ activity and inhibiting epithelial-mesenchymal transition. Oncotarget 7: 43588-43603, 2016.

34. Panzitt K, Tschernatsch MM, Guelly C, Moustafa T, Stradner M, Strohmaier HM, Buck CR, Denk H, Schroeder R, Trauner M and Zatloukal K: Characterization of HULC, a novel gene with striking up-regulation in hepatocellular carcinoma, as noncoding RNA. Gastroenterology 132: 330-342, 2007.

35. Bao $\mathrm{H}$ and $\mathrm{Su} \mathrm{H}$ : Long Noncoding RNAs Act as novel biomarkers for hepatocellular carcinoma: Progress and prospects. Biomed Res Int 2017: 6049480, 2017.

36. Zheng C, Hao H, Chen L and Shao J: Long noncoding RNAs as novel serum biomarkers for the diagnosis of hepatocellular carcinoma: A systematic review and meta-analysis. Clin Transl Oncol 19: 961-968, 2017.

37. George $\mathrm{J}$ and Patel T: Noncoding RNA as therapeutic targets for hepatocellular carcinoma. Semin Liver Dis 35: 63-74, 2015.

38. Ma L, Chua MS, Andrisani O and So S: Epigenetics in hepatocellular carcinoma: An update and future therapy perspectives World J Gastroenterol 20: 333-345, 2014.

39. Parasramka MA, Maji S, Matsuda A, Yan IK and Patel T: Long non-coding RNAs as novel targets for therapy in hepatocellular carcinoma. Pharmacol Ther 161: 67-78, 2016

40. Meijer D, van Agthoven T, Bosma PT, Nooter K and Dorssers LC: Functional screen for genes responsible for tamoxifen resistance in human breast cancer cells. Mol Cancer Res 4: 379-386, 2006.

41. van Agthoven T, Godinho MF, Wulfkuhle JD, Petricoin EF 3rd and Dorssers LC: Protein pathway activation mapping reveals molecular networks associated with antiestrogen resistance in breast cancer cell lines. Int J Cancer 131: 1998-2007, 2012.
42. Godinho MF, Wulfkuhle JD, Look MP, Sieuwerts AM, Sleijfer S, Foekens JA, Petricoin EF 3rd, Dorssers LC and van Agthoven T: BCAR4 induces antioestrogen resistance but sensitises breast cancer to lapatinib. Br J Cancer 107: 947-955, 2012.

43. Godinho M, Meijer D, Setyono-Han B, Dorssers LC and van Agthoven T: Characterization of BCAR4, a novel oncogene causing endocrine resistance in human breast cancer cells. J Cell Physiol 226: 1741-1749, 2011

44. Godinho MF, Sieuwerts AM, Look MP, Meijer D, Foekens JA, Dorssers LC and van Agthoven T: Relevance of BCAR4 in tamoxifen resistance and tumour aggressiveness of human breast cancer. Br J Cancer 103: 1284-1291, 2010.

45. Ju L, Zhou YM and Yang GS: Up-regulation of long non-coding RNA BCAR4 predicts a poor prognosis in patients with osteosarcoma, and promotes cell invasion and metastasis. Eur Rev Med Pharmacol Sci 20: 4445-4451, 2016

46. Li Q, Dai Y, Wang F and Hou S: Differentially expressed long non-coding RNAs and the prognostic potential in colorectal cancer. Neoplasma 63: 977-983, 2016.

47. Li N, Gao WJ and Liu NS: LncRNA BCAR4 promotes proliferation, invasion and metastasis of non-small cell lung cancer cells by affecting epithelial-mesenchymal transition. Eur Rev Med Pharmacol Sci 21: 2075-2086, 2017.

48. Shui X, Zhou C, Lin W, Yu Y, Feng Y and Kong J: Long non-coding RNA BCAR4 promotes chondrosarcoma cell proliferation and migration through activation of mTOR signaling pathway. Exp Biol Med (Maywood) 242: 1044-1050, 2017.

49. Wang L, Chunyan Q, Zhou Y, He Q, Ma Y, Ga Y and Wang X: BCAR4 increase cisplatin resistance and predicted poor survival in gastric cancer patients. Eur Rev Med Pharmacol Sci 21: 4064-4070, 2017.

50. Yang H, Yan L, Sun K, Sun X, Zhang X, Cai K and Song T: LncRNA BCAR4 increases viability, invasion and migration non-small cell lung cancer cells by targeting glioma-associated oncogene 2(GLI2). Oncol Res 27: 359-369, 2019.

51. Ouyang S, Zheng X, Zhou X, Chen Z, Yang X and Xie M: LncRNA BCAR4 promotes colon cancer progression via activating Wnt/beta $\beta$-catenin signaling. Oncotarget 8: 92815-92826, 2017.

This work is licensed under a Creative Commons Attribution-NonCommercial-NoDerivatives 4.0 International (CC BY-NC-ND 4.0) License. 